\title{
DRAGAGEM E CONFLITOS AMBIENTAIS EM PORTOS CLÁSSICOS E MODERNOS: UMA REVISÃO
}

\author{
Dredging and environmental conflicts in classic \\ and modern harbors: a revision
}

Silvia Machado de Castro

Geógrafa, Mestre em Engenharia Ambiental, UFRJ

smachado2009@gmail.com

Josimar Ribeiro de Almeida

Professor Associado, Escola Politécnica de Engenharia, UFRJ

almeida@poli.ufrj.br

Artigo recebido em 29/05/2012 e aceito para publicação em 25/08/2012

RESUMO: No Brasil, investimentos recentes em projetos de dragagem têm visado à ampliação da eficiência logística dos portos, incluindo obras de dragagem de aprofundamento, recuperação e melhoramento de vias de acesso, sendo imprescindível considerar os impactos positivos e negativos da atividade sobre o meio ambiente. Este trabalho objetiva fazer uma revisão dos principais impactos, tratamentos e usos benéficos dos sedimentos oriundos da obra ou serviço de dragagem portuária, como também os critérios de seleção dos locais para disposição do material dragado, os quais estão no centro de conflitos, pela possibilidade de atingirem ou mesmo eliminarem irreversivelmente ecossistemas aquáticos costeiros. Conflitos ambientais têm sido associados à obra de dragagem em portos clássicos e modernos, destacando a necessidade de uma agenda ambiental portuária que considere essas questões juntamente com grupos relevantes da sociedade no planejamento estratégico de ações para este setor.

Palavras-chave: Portos. Dragagem portuária. Conflitos ambientais.

ABSTRACT: In Brazil, recent investments on dredging projects have focused on the improvement of logistic efficiency of harbors, including dredging works to deepen, to recuperate and to improve of access ways, being indispensable to consider positive and negative impacts from that active over environment. The latter players object to make a revision about the principal impacts, treatments and benefic uses of the sediments derived of harbor dredging' works or services, as well as the classification of their degree of contamination, which are in the inner of conflicts and can impact or eliminate irreversibly coastal aquatic ecosystems. Environmental conflicts are being associated with dredging works, in harbors classified as classic and modern, pointing out the necessity to implement a harbor environmental agenda which considers these questions and the participation of relevant social groups on the elaboration of the strategic planning of actions for the harbor sector.

Key-word: Harbors. Harbor dredging. Environmental conflicts. 


\section{INTRODUÇÃO}

Considera-se porto o conjunto de instalações com funções de abrigo, atracação, armazenagem e circulação em terra e mar (acessos marítimos), localizado em um território denominado sítio portuário (PORTO e TEIXEIRA, 2002). O porto clássico ou porto-cidade é aquele localizado em metrópoles, abrigado em continente, com acesso marítimo de baixas profundidades e terrestre restrito, hinterlândia bem próxima e movimentação de carga geral não unitizada. O porto moderno é logístico, com rotas internacionais, a maioria em zonas costeiras, que movimenta cargas na forma especializada, tem pouca relação com seu entorno e áreas de influência longínquas, tem Áreas Marítimas Desenvolvidas Industrialmente, extensa retroárea e facilidade de desenvolvimento dos acessos terrestres (PORTO, 2007; 2008).

Intensas e constantes, as atividades desenvolvidas em um porto geram perturbações com consequências sobre o meio ambiente, este entendido como um conjunto de condições, leis, influências e interações de ordem física, química e biológica, que permitem, abrigam e regem a vida em todas as suas formas (BRASIL, 1981), exigindo-se, cada vez mais, mecanismos de gestão ambiental eficientes.

A dragagem, realizada para a limpeza, desobstrução, remoção, derrocamento ou escavação de material do fundo de rios, lagos, mares, baías e canais, removendo rochas e sedimentos, para lançamento em local de despejo (MARINHA DO BRASIL, 1998, BRASIL, 2007), é uma necessidade não somente para implantação, aprofundamento ou manutenção, mas também para a remediação, que tem como propósito limpar e recuperar áreas com sedimentos contaminados (GOES FILHO, 2004), que, no entanto, gera conflitos.

Conceitua-se conflito ambiental a disputa de grupos sociais pelo uso de recursos físico, social ou moral do meio em que vivem. Por isso mesmo, conflitos socioambientais envolvem necessariamente questões valorativas, que devem ser solucionadas pelo entendimento das necessidades coletivas (COSTA, 2009).

Os conflitos ambientais por dragagem portuária relacionam-se com o nível de contaminação dos sedimentos dragados e com o local selecionado para o despejo, que podem gerar danos à biota aquática, com reflexos sobre a qualidade de vida de atores regionais que, embora vivam num ambiente comum, possuem interesses antagônicos (THEODORO, 2005).

Qual a composição dos sedimentos dragados? Quais são os impactos ambientais negativos ou de que forma essa obra ou serviço de engenharia pode afetar habitats da fauna e flora aquática, além de atividades socioeconômicas? Quais os tratamentos e usos benéficos do material dragado? Existem conflitos ambientais associados à dragagem portuária? Se existem, são importantes para identificar e prevenir problemas e, desse modo, gerar soluções?

\section{MATERIAL DRAGADO}

Material dragado é aquele que é retirado ou deslocado do leito dos corpos d'água pela atividade de dragagem, desde que não constitua bem mineral (CONAMA, 2004). Na sua composição predominam partículas minerais, que variam de areia grossa a fina, silte e argila; também matéria orgânica e diferentes tipos de materiais como pedras, madeira, pedaços de metais, vidros etc. (CASTIGLIA, 2006; MONTEIRO, 2008).

Resíduos e rejeitos de dragagem são compostos orgânicos halogenados, plásticos, mercúrio, cádmio, petróleo, óleos, substâncias radioativas e outras substâncias produzidas para a guerra química e biológica. Na dragagem, deve-se dar atenção também aos resíduos com quantidades consideráveis de arsênio, zinco, cobre, fluoretos e pesticidas (LONDON [DUMPING] CONVENTION, 1972).

Algumas alternativas para disposição dos resíduos de dragagem são: (i) em corpos hídricos abertos, como oceanos, estuários, rios e lagos, que não estejam isolados das águas adjacentes durante o processo. Nesse caso, os resíduos devem estar limpos ou moderadamente contaminados; (ii) em mar aberto, são consideradas duas opções: em água profunda, além da plataforma continental, e na própria plataforma continental; (iii) em locais confinados ou áreas de disposição confinadas, sejam em corpos hídricos, como depressões na região costeira ou retidos entre diques, sejam em terra, destinado, principalmente, ao 
sedimento dragado contaminado, que necessita de controle, monitoramento ou manejo da área de estocagem ou mesmo aterro (GOES FILHO, 2004; ALMEIDA, 2004; CASTIGLIA, 2006; TORRES, 2000).

\section{IMPACTOS AMBIENTAIS NEGATIVOS DA DRAGAGEM}

O Conselho Nacional do Meio Ambiente define impacto ambiental como:

qualquer alteração das propriedades físicas, químicas e biológicas do meio ambiente, causada por qualquer forma de matéria ou energia resultante das atividades humanas que, direta ou indiretamente, afetam a saúde, segurança, bem estar da população; as atividades sociais e econômicas; a biota; as condições estéticas e sanitárias do meio ambiente; e a qualidade dos recursos ambientais. (Art. $1^{\circ}$ da Resolução CONAMA N $\left.{ }^{\circ} 001 / 1986\right)$

Consistem impactos ambientais por obra de dragagem, com efeito direto ou indireto sobre o meio ambiente (OECD, 1993; LEAL NETO, 2000; PORTO \& TEIXEIRA, 2002; TORRES, 2000):

a) alteração das condições hidráulicas e sedimentológicas do escoamento, com possível alteração dos padrões de circulação e mistura da água, salinidade e turbidez;

b) alteração das condições do local de lançamento do material dragado;

c) poluição por substâncias tóxicas existentes no material de dragagem, sua suspensão e movimentação durante a atividade, com alteração da qualidade da água (turbidez); e

d) impactos diretos sobre habitats da fauna e flora aquática, associada ao sedimento marinho e águas interiores.

A ação das dragas e a sucção do material geram impactos negativos de efeito direto sobre organismos e habitats. $\mathrm{O}$ efeito indireto ocorre com a movimentação de contaminantes e nutrientes durante a suspensão do sedimento, podendo haver alteração da qualidade da água e a química global do estuário (TORRES, 2000).
A qualidade do ar e do som na área portuária relaciona-se com a concentração de atividades, dentre muitas, a dragagem de baías, canais e berços de atracação. Vapores e gases são emitidos por navios, por equipamentos de manuseio e por transporte de carga como navios-dragas, caçambas e caminhões na retirada e transporte de sedimentos para a área de bota-fora ou de estocagem. Poeira, gases e maus odores, principalmente, os níveis de Dióxido de Enxofre $\left(\mathrm{SO}_{2}\right)$ e de Dióxido de Nitrogênio $\left(\mathrm{NO}_{2}\right)$, além de particulados em suspensão como fuligem, fumaça e vapor, poluem o ar. Os odores podem ser gerados pela movimentação da carga de material dragado contaminado, líquida e/ou sólida, para os locais de disposição e/ou estocagem. Perturbações por ruídos e vibrações a níveis e frequência elevados podem estar relacionados à dragagem de derrocamento ou desagregação de material para a extração de minério ou remoção de rochas submersas com explosivos, que geram ruídos e ondas de choque (LEAL NETO, 2000; CASTRO, 2012).

Em algumas áreas de bota-fora, quando o despejo das dragagens é efetuado na maré vazante, os impactos na região costeira são irrelevantes, porém, efetuados na maré enchente, se o material é grosseiro, poderá originar uma nuvem de poluição, que se direcionará para a costa e se sedimentará, podendo diminuir o potencial pesqueiro (CDRJ, 2002). Problemas decorrentes da disposição de material dragado no mar também podem gerar risco à navegação, à atividade pesqueira, de turismo e lazer, com reflexo sobre aspectos culturais (FEEMA, 2002). Considera-se também a possibilidade de acidentes de dutos e cabos submarinos, que podem depositar sedimento dragado contaminado em local inadequado gerando impactos negativos ao meio ambiente (ALMEIDA, 2008).

\section{TRATAMENTOS E USOS BENÉFICOS DO RE- SÍDUO DE DRAGAGEM}

Em se tratando de gestão ambiental de atividades portuárias, a prevenção como forma de antecipar soluções diante de algo que se sabe que ocorrerá ou poderá ocorrer com base em estimativas e algum conhecimento sobre o que se pretende prevenir, seus efeitos e modos de ocorrência (BARBIERI, 2007), é o melhor a fazer. O monitoramento da qualidade da 
água e dos sedimentos, além da seleção criteriosa do local de despejo ou bota-fora, são medidas de prevenção. $\mathrm{O}$ próprio investimento em conhecimento é uma medida de prevenção, eliminando a necessidade de se tomar medidas de precaução (PORTO, 2012). Pode-se afirmar que a legislação ambiental brasileira mitiga impactos ambientais quando estabelece normas e procedimentos para o licenciamento ambiental (CASTRO, 2012).

São vários os tratamentos (Quadro 1) e usos benéficos do sedimento dragado, suavizando o dano.
O tratamento consiste em processar o material dragado contaminado com vistas a reduzir a concentração dos contaminantes, a fim de atenderem aos padrões estabelecidos pela legislação, no caso brasileiro, da Resolução CONAMA No 344 (CONAMA, 2004). Anteriormente considerados dispendiosos, com a Política Nacional de Resíduos Sólidos (PNRS) o tratamento, reciclagem e reuso de resíduos tornam-se obrigatórios, cabendo às Autoridades Portuárias atender seus princípios e diretrizes (BRASIL, 2010).

Quadro 1 - Processos de tratamento dos materiais contaminados

\begin{tabular}{|c|l|}
\hline TRATAMENTO & \multicolumn{1}{c|}{ ESPECIFICIDADE } \\
\hline Pré-tratamento & $\begin{array}{l}\text { Redução de volume do material dragado através da separação de partículas de } \\
\text { diferentes tamanhos, resultando na secagem e compactação do material sólido; pode } \\
\text { ser com o uso de bacias de separação, hidrociclones, flotação, desidratação e separação } \\
\text { magnética. Usam-se geotubos, geobolsas e cortinas de geotêxtil. }\end{array}$ \\
\hline Físico-químico & $\begin{array}{l}\text { Utiliza processos químicos na remoção, alteração e estabilização dos contaminantes. } \\
\text { Aplicam-se técnicas de extração ácida, de complexos, de solventes efluída supercrítica; } \\
\text { técnicas de imobilização, de oxidação através da umidade do ar, de destruição de } \\
\text { Bifenilas Policloradas (BPC) e de troca iônica. }\end{array}$ \\
\hline $\begin{array}{c}\text { Biológico ou } \\
\text { degradação } \\
\text { biológica }\end{array}$ & $\begin{array}{l}\text { Busca o aumento da quebra natural de contaminantes orgânicos em compostos } \\
\text { inofensivos através dos microrganismos; pode-se realizar fora do local de deposição, } \\
\text { através do cultivo apropriado do solo e biorreatores, o que depende da temperatura, } \\
\text { umidade e disponibilidade de nutrientes; a biorremediação busca descontaminar solo } \\
\text { e água por meio de organismos vivos e, a fitorremediação, visa a remediação de áreas } \\
\text { contaminadas com plantas, solo e práticas agronômicas. }\end{array}$ \\
\hline Térmico & $\begin{array}{l}\text { Remove, destrói e imobiliza certos contaminantes; deve ser precedido da desidratação } \\
\text { e secagem dos sedimentos; ocorre através de dissociação térmica, incineração e } \\
\text { imobilização térmica. }\end{array}$ \\
\hline Eletrocinético & $\begin{array}{l}\text { Aplicação de corrente constante em solo saturado com contaminantes, resultando no } \\
\text { armazenamento de íons metálicos e outros cátions no catodo e dos anions, no anodo } \\
\text { positivo; permiti a remoção in situ dos metais pesados, evitando manejo e contenção } \\
\text { do mesmo. }\end{array}$ \\
\hline imobilização & $\begin{array}{l}\text { O dragado pastoso com contaminantes é estabilizado e solidificado aplicando-se } \\
\text { cimento ou pó de cal. }\end{array}$ \\
\hline
\end{tabular}

Fontes: Goes Filho (2004); Monteiro (2008); Coutinho \& Barbosa (2007); Tavares (2009); Farra \& Rodríguez (2003); Lundin, Escobar \& Stephens, 2006; e Castro, 2012.

O solo dragado tem grande poder de manejo e gerenciamento com benefícios ambiental, social e econômico. O uso do rejeito contaminado, no entanto, deve ser evitado na formação de habitats e na produtividade biológica (MONTEIRO, 2008).

A aprovação do local de disposição é cada vez mais restrita, já que os sedimentos dragados, principal- 
mente os resultantes da manutenção de portos, canais, rios e lagos, podem apresentar médio ou alto grau de contaminação (CASTIGLIA, 2006).

Para uso benéfico, deve ser considerada a composição e distribuição granulométrica do material dragado, além das condições de remoção, sua aceitabilidade ambiental e custos para o processo (GOES FILHO, 2004).

São algumas alternativas de manejo e uso benéfico do rejeito de dragagem (MONTEIRO, 2008):

a) construção de aterros, mais econômico e ambientalmente aceito do que dispor no mar ou em terra;

b) engordamento ou alimentação de praia, solução para reposição de sedimento perdido pela erosão costeira, grande problema para as praias oceânicas e estuarinas;

c) restauração e formação de habitats, no estabelecimento da produtividade biológica de plantas e animais em ilhas construídas com essa finalidade;

d) pântanos, em cujo substrato predomina a areia de granulometria mais fina; requer a contenção do material através de estruturas ou mecanismos de proteção;

e) terras elevadas, que são habitats com grande variedade de comunidades terrestres, desde um solo exposto até uma floresta; localizados em pequenas ou grandes áreas naturais ou construídas para adaptação à vida silvestre ou urbana;

f) habitat aquático, cujo desenvolvimento depende do estabelecimento de comunidades biológicas, através do material dragado na superfície ou abaixo da maré, em áreas costeiras ou em lagos e rios, geralmente aplicado para ostras, peixes, gramíneas, mariscos, moluscos e plantas aquáticas;

g) agricultura, na formação de pastagens para gado e para melhorar a qualidade dos solos marginais para fins agrícolas;

h) recuperação de áreas de mineração, controle da drenagem ácida da superfície, como também da erosão e a velocidade da água, favorecendo o estabelecimento de plantas na área;

i) cobertura em aterros de resíduos sólidos, linhas, barreiras para gás, drenos de lixiviados ou de gás, condicionados às características físicas do aterro; e j) usos múltiplos, construção de áreas recreativas sobre aterros controlados, habitats de espécies silvestres, matéria prima da indústria de construção civil, material combustível (gás) e substrato para a produção de biomassa vegetal.

Outro uso do sedimento dragado tem sido na manufatura do cimento de Portland, devido à grande quantidade de sílica, alumínio, cálcio e óxidos de ferro, importantes na constituição do cimento (DUBOIS et al., 2009). Na construção de estradas, esse sedimento necessita de redução de sais e matérias orgânicas. A descontaminação do solo dos metais pesados tem sido realizada pela técnica de ultrassonda acoplada à pressão a vácuo (ZENTAR, ABRIAK \& DUBOIS, 2009).

\section{GESTÃO AMBIENTAL PORTUÁRIA}

A gestão ambiental dos portos organizados e demais instalações portuárias do país deve se basear num modelo institucional com uma estrutura gerencial ágil e adequada, que privilegie a articulação entre todas as autoridades envolvidas e tenha como funcionamento a Lei de Modernização dos Portos e a legislação ambiental (CIRM, 1998).

O objetivo é atingir elevados padrões de proteção ambiental dentro de um conceito de desenvolvimento sustentável, através da formação de núcleo ambiental, o qual deve reunir profissionais capacitados para equacionar problemas: no mínimo, um engenheiro, um biólogo e um oceanógrafo; num grupo expandido, um químico, um urbanista ou arquiteto ou geógrafo, um advogado e um economista (ANTAQ, 2007; 2008).

O relatório de agosto de 2011 da Agência Nacional de Transportes Aquaviários (ANTAQ, 2011) indicou uma contínua evolução do desempenho ambiental dos portos brasileiros justificada, dentre outras coisas, pela entrada em vigor de novas diretrizes e exigências legais; compromissos internacionais assumidos pelo Estado do porto; ao uso de tecnologias mais limpas e eficientes nas operações portuárias; a uma melhor qualificação dos profissionais para tratar das questões ambientais; uma busca cada vez maior da sociedade por produtos e serviços ambientalmente sustentáveis; e a uma atuação mais participativa dos órgãos reguladores ambientais no processo de 
construção e implementação de um modelo de gestão ambiental portuária.

Na comparação entre os períodos de 2009/2010 e 2006/2007, a avaliação da gestão ambiental dos portos públicos brasileiros identificou que mais três portos obtiveram a Licença de Operação (LO); maior proporção de atendimento pleno pelos portos em relação à implantação de um Plano de Emergência Individual (PEI), preconizado na Lei $\mathrm{N}^{\circ}$ 9.966, de 28 de abril de 2000 e na Resolução CONAMA N ${ }^{\circ}$ 398, de 11 de junho de 2008, que tratam da poluição por óleo em águas jurisdicionais; maior proporção de atendimento pelos portos em relação ao correto gerenciamento de resíduos sólidos, incrementada pela publicação da Lei $N^{o} 12.305 / 2010$, que instituiu a PNRS; e a auditoria ambiental compulsória, regrada pela Resolução CONANA No 306/2002, deixou de ser realizada corretamente em alguns portos.

São duas as prováveis causas do resultado negativo em relação à auditoria ambiental: o pequeno número de auditores qualificados para realizá-la; ou a não observância do porto em atualizá-la de dois em dois anos, conforme se obriga.

Em relação à implantação e qualificação de núcleos ambientais nos portos, a comparação entre esses dois períodos indicou um resultado negativo, justificado, segundo essa mesma agência, pela publicação da Portaria SEP No 104/2009, que obriga a redefinição da estrutura organizacional portuária, de forma a instituir o Setor de Gestão Ambiental e de Segurança e Saúde no Trabalho (ANTAQ, 2011).

A introdução da questão ambiental no dia a dia do porto faz-se através de medidas de ordenação como a adoção de regulamentos sobre preservação, conservação e valorização do meio ambiente. De cunho estratégico, a Agenda Ambiental molda um desempenho a ser cumprido pelas Administrações de Portos e outras entidades exploradoras de instalações portuárias, dentro e fora dos portos organizados (MT, 2001, p. 75).

\section{Agenda Ambiental Portuária}

Em 19 de março de 1998, foi criado, através da Portaria SECIRM No 005, o Subgrupo Agenda Ambiental Portuária (AAP). Em 2 de dezembro de
1998, essa agenda foi elaborada e aprovada no âmbito do Grupo de Integração do Gerenciamento Costeiro (GI-GERCO) e aprovada pela Comissão Interministerial para os Recursos do Mar (CIRM), da MB, através da Resolução No 006/98/CIRM, como proposta para adequar o setor portuário aos parâmetros ambientais vigentes com vistas a estabelecer mecanismos de acompanhamento e o cumprimento de normas de preservação ambiental em todos os portos e instalações portuárias, iniciou-se a preparação de uma Agenda Ambiental. A partir da aprovação desse documento, iniciou-se a conciliação da atividade portuária com a preservação ambiental.

Na AAP federal são apresentadas: Propostas de Modelo Institucional para a Gestão Ambiental Portuária; Procedimentos para a Implementação da Gestão Ambiental Portuária; e Ações Programadas para a Implementação da AAP. A gestão ambiental dos portos organizados e demais instalações do País deveria se basear "num modelo institucional com uma estrutura gerencial ágil e adequada, que privilegie a articulação entre todas as autoridades envolvidas, fundamentado na Lei de Modernização dos Portos e na legislação ambiental" (CIRM, 1998, p. 5).

Em se tratando do controle ambiental da atividade portuária, padrões de procedimentos precisam ser firmados visando evitar impactos ao meio ambiente, constituindo-se uma das metas a obtenção das certificações da International Organization for Standardization (ISO) séries 9.000 e 14.000. Sua implantação deve ocorrer a partir de programas, tais como: monitoramento ambiental; controle de erosão e assoreamento, incluindo o gerenciamento das dragagens; risco ambiental e prevenção de acidentes (análises de risco, plano de contingências); Plano de Controle Ambiental (resíduos sólidos, efluentes líquidos e emissões); controle da introdução de espécies marinhas exóticas, através da água de lastro; e conservação dos recursos naturais (pesca e ecossistemas costeiros na área de influência do porto).

Uma revisão periódica, a fim de adequar a AAP às realidades institucionais e financeiras, deve considerar: atualização da legislação ambiental; inclusão das relações ambientais porto-cidade; implantação de agendas ambientais institucionais, local 
e da organização portuária, com o comprometimento dos agentes intervenientes; alocação de recursos para a gestão ambiental da infraestrutura portuária (ambiente antrópico e natural); e realização de inventários ambientais portuários, acerca dos recursos (inclusive relações) ambientais envolvidos ou a serem envolvidos na atividade (PORTO, 2008). Seu papel é estar atenta não somente às demandas de mercado como também às demandas ambientais, além de adotar um papel mais responsável frente à sociedade. Nesse sentido, a dragagem como obra de melhoramento da parte externa do porto, requer planejamento com foco em ações preventivas para a minimização de impactos ambientais.

\section{Agenda Ambiental Local}

A idéia de uma Agenda Ambiental Local (AAL) é de um plano de ação pactuado com os principais atores regionais, com base no diálogo com as agências ambientais, governos locais, movimentos ambientalistas e outros grupos de interesse, pescadores e outros segmentos econômicos diretamente interessados na atividade portuária e/ou em seus desdobramentos nos ambientes de utilização comum, cabendo à iniciativa de sua elaboração à Autoridade Portuária (ANTAQ, 2009).

Análoga à AAP, a AAL deve ajustar as atividades do porto às conformidades ambientais e capacitar agentes para equacionar os problemas ambientais decorrentes, objetivando a valorização de seus ambientes. Para tanto, é necessário que haja envolvimento desses atores; disponibilidade e manuseio de informações técnicas e científicas sobre os impactos ambientais; experiência de uma equipe multidisciplinar; uma boa agenda de marketing; metas e prazos para tarefas estabelecidas; e base institucional e organizacional para implantação.

A estrutura de uma AAL deve incluir: (i) caracterização do porto e de suas atividades, destacando-se informações sobre sua situação institucional, dados sobre os documentos de licenciamento e sobre possíveis disputas e pendências judiciais de natureza ambiental e outras intervenientes; (ii) elaboração do diagnóstico ambiental, com informações sobre o meio natural, sua hidrodinâmica, os principais ecossistemas e influências positivas e negativas sobre eles; a identificação de passivos ambientais; e a identificação de problemas ambientais atuais, relacionando os tipos e locais das principais fontes de poluição no porto e em suas áreas de influência; (iii) elaboração do diagnóstico de segurança e saúde ocupacional; (iv) elaboração de propostas de ação, definindo, entre outras coisas, os objetivos da Agenda, identificando as situações-problemas e os atores e agentes intervenientes ou mobilizáveis, em face das ações programadas, especificando mecanismos de articulação disponíveis ou a serem criados; e o gerenciamento da Agenda, para avaliar, acompanhar, monitorar o desempenho de suas ações, definir estratégias para sua implantação e do cronograma das ações previstas.

Este é um padrão geral, podendo todos os portos formular a estrutura que melhor se adéqua às suas peculiaridades.

\section{Agenda Ambiental Institucional}

A Agenda Ambiental Institucional (AAI), embora não sendo um dispositivo de lei, constituise num instrumento da vontade de dirigentes em promover a qualidade ambiental da sua atividade, fator indutor de um processo de mudança especialmente da imagem da organização associada à proteção e valorização do seu meio ambiente. A AAI está inserida no contexto de dois outros instrumentos de mesma natureza, também não compulsórios, como a AAL (do porto) e a AAP (federal), em conformidade com outros instrumentos de gestão. Na sua elaboração deve-se considerar a visão estratégica do mercado, no caso, das instituições portuárias ambientalmente orientadas, na incorporação integrada dos aspectos econômicos, sociais e ambientais de suas atividades, antecipando formas de lidar com a sociedade consumidora de seu produto (ANTAQ, 2011).

Uma AAI adequadamente estruturada atende tanto ao ambiente externo como ao interno da organização: o primeiro diz respeito à relação da organização com a sociedade no sentido mais amplo e com a comunidade portuária; no âmbito interno, não se deve deixar de lado ações em favor da sustentabilidade que incorporem o discurso externado à sociedade, tudo de forma bastante clara, fazendo 
valer todos os elementos estruturantes da Agenda, que são: missão; política; objetivos estratégicos; objetivos específicos; diretrizes; metas; planos e programas; Sistema de Gestão Ambiental (SGA); e índice de qualidade ambiental.

Os produtos associados a esse processo são: a melhoria da imagem da organização, da eficiência na prestação dos serviços, da competitividade e da qualidade do ambiente interno; redução de custos e riscos ambientais; atração de novos mercados consumidores; e aumento da confiabilidade da organização, não necessariamente nessa sequência. Sua adoção, pela organização, portuária ounão, produz resultados positivos, tais como: o desenvolvimento de novas lideranças mais conscientes e socialmente responsáveis; melhor clima organizacional; melhor satisfação e motivação dos funcionários; aumento da autoestima de todos os participantes; e reconhecimento e orgulho pela participação em projetos sociais.

\section{CONFLITOS AMBIENTAIS}

Falar de conflitos é falar das relações humanas, que envolvem valores morais ou tudo aquilo que pertence ao caráter. $\mathrm{O}$ ambiental reporta à natureza $\mathrm{e}$ tudo que nela existe, inclusive o indivíduo com seus valores sociais, conhecimentos, habilidades, atitudes e competências. Os problemas ambientais da sociedade humana resultam da sua organização econômica e social e, qualquer problema aparentemente extremo, se apresenta primeiro como um conflito, demandando soluções equilibradas, ou seja, com ganho para ambas as partes. Isso, no entanto, é de difícil alcance (FOLADORI, 2001).

O conflito, na verdade, deve ser encarado como um dos elementos de construção da própria democracia, para que ocorra a valorização de espaços de tensão e negociação, legítimos e relevantes avanços de cooperação no sentido da coesão social (COSTA, BURSZTYN \& NASCIMENTO, 2009).

Existem muitos métodos de resolução de conflitos, mas a construção de consenso, a mediação e o diálogo público têm sido os mais utilizados para questões ambientais (BREDARIOL, 2001). É um direito da sociedade organizada o acesso à informa- ção ambiental, assim como a participação social na elaboração de políticas ambientais. Ela encontra nas audiências públicas uma das formas de participação e de controle popular da administração pública no estado social e democrático de direito e, no Ministério Público, o poder fiscalizador da aplicação das leis, da defesa do patrimônio público e do zelo pelo efetivo respeito dos poderes públicos aos direitos assegurados na Carta Magna, inclusive a proteção do meio ambiente (MINISTÉRIO PÚBLICO FEDERAL, 2012).

\section{DRAGAGEM E CONFLITOS AMBIENTAIS EM PORTOS CLÁSSICOS E PORTOS MODERNOS}

A seguir, dois casos de portos clássicos e dois de portos modernos brasileiros, em que há registros de conflitos em torno de impactos ambientais e sociais por obra de dragagem. São eles: Porto de Tubarão, no Espírito Santo; Porto do Rio de Janeiro e Complexo Industrial do Superporto do Açu, no Rio de Janeiro; e Complexo Industrial Portuário de Suape, em Pernambuco.

\section{Porto de Tubarão}

O Complexo Portuário de Tubarão (também denominado Terminal ou Porto de Tubarão) foi inaugurado em 1966 e está localizado na Ponta de Tubarão e administrado pela Companhia Vale do Rio Doce (hoje VALE S.A.). Para a dragagem de aprofundamento, iniciada em janeiro de 2011 com o propósito de oferecer acesso a embarcações com calado de 25,3 metros no Píer II e no Terminal de Carvão do Porto de Praia Mole, ou seja, um aumento de 600 metros na extensão do canal de acesso e uma ampliação de 130 metros na bacia de evolução, estima-se a movimentação de cerca de 7 milhões de $\mathrm{m}^{3}$, incluindo a derrocagem de cerca de $150 \mathrm{mil} \mathrm{m}^{3}$ (VALE/CEPEMAR, 2010; ZANDONADI, 2011).

O processo de licenciamento ambiental e os impactos negativos da dragagem e da disposição do sedimento dragado sobre a biodiversidade marinha regional, como também sobre atividades socioeconômicas, foram questionados durante a audiência pública realizada em Vila Velha no dia 27 de maio de 2010. Naquela ocasião, foram esclarecidas as características 
da obra como também apresentadas algumas preocupações de ambientalistas e moradores da região, tais como: a localização da área de bota-fora ou área de despejo; os danos causados no ecossistema de manguezal da Baía de Vitória, a ser compensado com ajuda financeira para a criação/manutenção de Unidade de Conservação; e a toxicidade dos sedimentos e possíveis danos ao meio biótico e abiótico, com reflexos sobre atividades de pesca e lazer na área de influência do empreendimento. Segundo eles, faltou uma ampla divulgação da audiência pública, o Conselho Comunitário e a Câmara Municipal local não estavam presentes; não houve participação das comunidades pesqueiras no Estudo de Impacto Ambiental; e faltou consulta prévia à sociedade sobre a forma e local de despejo em Vila Velha (GOVERNO DO ESTADO DO ESPÍRITO SANTO, 2010).

A dragagem da Baía de Vitória, cujo edital de licitação foi publicado em setembro de 2011, visa à contenção e ampliação do cais comercial do Porto de Vitória para a entrada de navios maiores, através da remoção de cerca de 15 milhões de $\mathrm{m}^{3}$ de sedimentos (CODESA, 2012). Essa obra também tem sido contestada, principalmente, por ser a área de despejo em Vila Velha, ou seja, a mesma área de bota-fora dos materiais dragados no Porto de Tubarão (BERNARDES, 2011).

\section{Porto do Rio de Janeiro, RJ}

Inaugurado há 112 anos, o Porto do Rio de Janeiro situa-se ao sul da Baía de Guanabara e é administrado pela Companhia Docas do Rio de Janeiro, que também administra os portos de Niterói, de Itaguaí e de Angra dos Reis (CDRJ, 2012).

Entre fevereiro de 2010 e setembro de 2011, foi realizada a primeira fase da dragagem de aprofundamento dos canais de acesso interno e externo das bacias de evolução dos cais da Gamboa, São Cristóvão e Caju (incluindo o Canal do Mangue), que retirou 3,9 milhões de $\mathrm{m}^{3}$ de sedimentos, sendo $30 \mathrm{mil} \mathrm{m}^{3}$ de material contaminado para tratamento na Ilha da Pombeba, e o restante para lançamento em área oceânica (CDRJ, 2011).

Conflitos surgiram em torno dos impactos e possíveis danos à biota da Baía de Guanabara e Região Oceânica de Niterói, RJ, onde inclusive se loca- liza o Monumento Natural do Arquipélago das Ilhas Cagarras, uma Unidade de Conservação de proteção integral, pela disposição de sedimento contaminado da última dragagem do Porto do Rio de Janeiro, em área oceânica. Pescadores artesanais, assim como a sociedade organizada de Niterói e Maricá, alertam sobre os níveis de poluição da água, degradação dos ecossistemas aquáticos e perda da qualidade de vida, com reflexos sobre a economia familiar, turismo e lazer da região. São suas principais reivindicações: condicionar a seleção da área de bota-fora a uma avaliação prévia da qualidade da biota e da produtividade pesqueira; acesso prévio às informações do projeto de dragagem; e condicionar o licenciamento ambiental de obras de dragagem no Porto do Rio de Janeiro a uma avaliação prévia da pesca e efeitos negativos do material dragado sobre a atividade pesqueira, com base em análise prévia da ecotoxicologia da área de bota-fora (CASTRO, 2012).

Nessa primeira fase da dragagem, alguns trechos alcançaram profundidade de -15 metros. A segunda fase, ainda em licitação, prevê o aprofundamento de até -17 metros em algumas áreas (VIEIRA, 2011). $\mathrm{O}$ volume de material a ser dragado nessa segunda fase ainda não está confirmado.

\section{Complexo Industrial do Superporto do Açu, RJ}

Exemplo de porto moderno, o Complexo Industrial do Superporto do Açu, em Açu, distrito do município de São João da Barra, RJ, engloba: a construção de um terminal portuário privativo de uso misto composto por seis berços de atracação de navios e píeres off-shore, com acesso por meio de um canal com 18,5 metros de profundidade, para receber navios de grande porte, com capacidade de transporte de cargas até 220 mil toneladas; além de quatro berços para atracação de embarcações de apoio às atividades de exploração de petróleo na região. A retro-área deverá abrigar um complexo siderúrgico, usinas termoelétricas, plantas de pelotização de minério, pólo metal-mecânico, além de áreas para trancagem de granéis líquidos e processamento de petróleo. O Terminal Portuário deverá contar também com um mineroduto, que transportará de Minas Gerais até lá minério de ferro para exportação (LLX, 2012). 
A região será ocupada por outros empreendimentos, formando um Complexo Logístico e Industrial nas divisas dos municípios de Campos dos Goytacazes e Quissamã e, com isso, o crescimento econômico regional certamente será favorecido, porém os impactos ambientais negativos não podem ser desconsiderados.

População, agricultores e pescadores artesanais da região estão preocupados com a possibilidade de danos ambientais pela dragagem de implantação e aprofundamento, como também as futuras dragagens de manutenção. Esses trabalhadores já prevêem a mortalidade de espécies marinhas e a expulsão dos peixes, como também registram perda de equipamentos de trabalho, o que poderia ser evitado ou minimizado por um diagnóstico eficiente sobre essas atividades na região (KURY, REZENDE e PEDLOWSHI, 2010; SOUZA e OLIVEIRA, 2010).

A implantação de uma Agenda Ambiental Local, como um plano de ação pactuado com os principais atores regionais; o uso da abordagem dos ganhos mútuos, que propõe a ultrapassagem de um padrão de jogos de soma zero, para administrar os conflitos; e a organização, nesse caso, da classe de pescadores da região, pois a desestruturação impede o desenvolvimento pleno de programas e projetos adequados para a comunidade, pelo enfraquecimento do poder de reivindicação e de participação associado à organização incipiente, são medidas que podem solucionar os impasses (SOUZA e OLIVEIRA, 2010).

Para a abertura do porto TX2, que faz parte desse empreendimento, o total de volume previsto na obra de dragagem de um canal de entrada e um canal interno, de uma bacia de manobras e da bacia do porto, deverá chegar a 43 milhões de $\mathrm{m}^{3}$, sendo que uma parte será usada para o aterro de terrenos para construção de instalações portuárias (BARRA EM NOTÍCIAS, 2011).

\section{Complexo Industrial Portuário de Suape, PE}

O Complexo Industrial Portuário Eraldo Gueiros, ou simplesmente Suape, é um pólo para localização de negócios industriais e portuários, que conta com um porto interno, externo, cais de múltiplos usos, terminais de granéis líquidos, além de um terminal de contêineres e agregar diversas outras modalidades de transportes, com rodovias e ferrovias internas e um porto de águas profundas, possuindo toda uma estrutura de comunicação e serviços. A posição geográfica de Pernambuco, no centro da Região Nordeste, transforma Suape em um centro concentrador e distribuidor de cargas. A localização também o torna com vocações de porto internacional concentrador de cargas ( $h u b$ port) para toda a América do Sul. O complexo, com características de porto moderno, é administrado pelo Governo do Estado de Pernambuco (GOVERNO DO ESTADO DE PERNAMBUCO, 2012).

Os conflitos ambientais relativos ao Suape, considerado um porto moderno, são discutidos desde 1975. O local escolhido para o projeto, numa área ao sul do cabo de Santo Agostinho, era povoado e tinha rios, praias, manguezais, matas, pomares e canaviais. A boa profundidade e disponibilidade de retro-área para a instalação e as atividades de um porto justificaram a "irreversibilidade da paisagem" (CAVALCANTI, 2008).

Apesar de representar um benefício socioeconômico para a região nordeste, a construção do porto e do terminal de trancagem gerou impactos ambientais que se "revelaram desastrosos" (SÁ, 2008), destacadamente a obstrução de um dos quatro rios (Ipojuca), transformando o estuário em uma laguna costeira (KOENING et al., 2002) e o desequilíbrio ecológico das espécies estuarino-costeiras (KITZMANN \& ASMUS, 2006). Com isso, marisqueiros e pescadores saem prejudicados em suas atividades.

$\mathrm{O}$ ordenamento urbano das comunidades que moravam lá antes da instalação do Complexo continua gerando conflitos que aguardam por solução (GOUVEIA, 2011). Vale ressaltar que muitos desses moradores têm relação direta com a pesca artesanal, dependendo dela para garantir a sobrevivência de suas famílias. Em janeiro de 2010, a dragagem de aprofundamento do canal interno do porto de Suape, teria lançado "dejetos (bota-fora) provenientes da dragagem (lama, barra de concreto, ferro...) em cima dos pesqueiros (cabeços e arrecifes naturais)", ameaçando "a continuidade da atividade pesqueira artesanal e deixando centenas de famílias sem condições de trabalho" (REDE MANGUEMAR - PE, 2010). Este é um impacto negativo aditivo de conflitos de natureza 
ambiental com reflexos social, econômico e cultural.

Duas dragagens de aprofundamento foram inseridas na primeira fase do PAC: a dragagem do canal interno foi concluída em maio de 2011, mobilizando cerca de $3,9 \mathrm{~m}^{3}$ mil de sedimentos; a dragagem de aprofundamento do canal externo iniciou em novembro de 2011, prevendo dragar cerca de $4,7 \mathrm{~m}^{3}$ mil (MPOG, 2011; 2012; GOVERNO DO ESTADO DE PERNAMBUCO, 2011).

\section{CONCLUSÕES}

A dragagem portuária é uma necessidade que demanda uma eficiente gestão ambiental do material dragado, em que se considere o monitoramento das condições dos elementos bióticos e abióticos, os tratamentos e usos possíveis dos resíduos de dragagem, como também fatores socioeconômicos da zona costeira com toda sua dinâmica de uso e ocupação.

A Agenda Ambiental Local deve buscar se enquadrar na política de gestão dos portos brasileiros para tratamento dos aspectos ambientais na perspectiva de uma gestão negociada, na forma de um importante instrumento no impedimento de conflitos ambientais entre os diversos atores do cenário portuário. No entanto, o desempenho das agências ambientais, as exigências para o licenciamento ambiental e seu tempo de tramitação também constituem fontes de conflito, exigindo disposição para o consenso na resolução das demandas.

Cabe lembrar que a responsabilidade pela poluição e pela necessidade de dragagem não é apenas dos portos, mas também das cidades. Nesse sentido, o planejamento do uso e ocupação do solo deve considerar os aspectos social e econômico nas questões ambientais.

Por outro lado, o acesso prévio às informações sobre projetos de dragagem portuária tem sido reivindicado por grupos tradicionais, que consideram a prévia avaliação da ecotoxicologia dos sedimentos e a seleção criteriosa dos locais de disposição uma forma de evitar ou minimizar possíveis danos à biodiversidade aquática e perda de fontes de sobrevivência. Nesse sentido, conflito deve ser visto como uma oportunidade de definir novas estratégias de desenvolvimento ou mesmo exercitar princípios democráticos nas relações sociais mediadas pela natureza. Os fatos são atuais e, por isso, recomenda-se não deixar escapar o momento propício para o diálogo sobre a questão, pois é dever de todos preservar e conservar, para esta e futuras gerações, os recursos naturais e a qualidade do meio ambiente.

\section{REFERÊNCIAS}

ALMEIDA, S. R. Subsidios para o Gerenciamento Ambiental de Projetos de Dragagem em Portos. Rio de Janeiro, Dissertação (Mestrado em Ciências em Engenharia de Transportes) - IME, 2004.

ALMEIDA, J. R. Gestão ambiental para o desenvolvimento sustentável. Rio de Janeiro: Thex, 2008.

AGÊNCIA NACIONAL DE TRANSPORTES AQUAVIÁRIOS. Relatório de Gestão Ambiental. Relatório Consolidado das Avaliações de 2006 e 2007 da Gestão Ambiental nos Portos Organizados. Brasília: Superintendência de Portos, Gerência de Meio Ambiente, 2007. Disponível em: http://www.antaq.gov. br/portal/PDF/MeioAmbiente/Relatorios/RelatorioConsolidado.pdf. Acesso em: 12 set. 2010.

Panorama 2008 do Transporte Aquaviário. Avaliação da Gestão Ambiental nos Portos Organizados. Brasília: Secretaria Especial de Portos, 2008.

. Agenda Ambiental Portuária. Disponível em: http://www.antaq.gov.br/portal/MeioAmbiente_AgendasAmbientais.asp. Acesso em: 02 jun. 2009.

. Porto Verde. Modelo Ambiental Portuário. s/d. Disponível em: http://www.antaq.gov.br/Portal/pdf/ PortoVerde.pdf. Acesso em: 15 mai. 2011.

BARBIERI, J. C. Gestão Ambiental Empresarial: conceitos, modelos e instrumentos - 2. ed. São Paulo: Saraiva, 2007.

BARRA EM NOTÍCIAS. Empresa holandesa fecha contrato de $€ 200$ milhões com as empresas LLX e OSX para o Super Porto do Açu. 2 de agosto de 2011. Barra em Notícias. Disponível em: http://barrafmnoti- 
cias.blogspot.com/2011/08/empresa-holandesa-fecha-contrato-de-200.html. Acesso em: jan. 2012.

BERNARDES, F. Ministro dos Portos anuncia licitação para dragagem da Baía de Vitória. 30 de setembro de 2011. Século Diário. Disponível em: http://seculo-diario.jusbrasil.com.br/politica/7786566/ ministro-dos-portos-anuncia-licitacao-para-dragagem-da-baia-de-vitoria. Acesso em: jan. 2012.

BRASIL. Lei $N^{\circ} 6.938$, de 31 de agosto de 1981. Institui a Política Nacional do Meio Ambiente. Disponível em: http://www.planalto.gov.br/ccivil_03/leis/L6938. htm. Acesso em: nov. 2011.

. Lei $N^{o} 11.610$, de 12 de dezembro de 2007. Institui o Programa Nacional de Dragagem Portuária e Hidroviária. Disponível em: http://www.planalto. gov.br/ccivil_03/_ato2007-2010/2007/Lei/L11610. htm. Acesso em: mai. 2011.

. Lei $N^{o} 12.305$, de 2 de agosto de 2010. Institui a Política Nacional de Resíduos Sólidos. Disponível em: http://www.planalto.gov.br/ccivil_03/_ato20072010/2010/lei/112305.htm. Acesso em: nov. 2011.

BREDARIOL, C. S. Controle Ambiental e Negociação para uma Política Local de Meio Ambiente. Rio de Janeiro, Tese (Doutorado em Engenharia de Planejamento) - COPPE/UFRJ, 2001.

CASTIGLIA, M. C. C. P. Disposição subaquática de rejeitos de dragagem: o caso do complexo lagunar de Jacarepaguá. Rio de Janeiro, Dissertação (Mestrado em Engenharia Civil) - COPPE/UFRJ, 2006.

CASTRO, S. M. Conflitos ambientais e participação social em processos de AAE para o setor portuário: dragagem em foco. Rio de Janeiro, Dissertação (Mestrado Profissional em Engenharia Ambiental) - UFRJ, 2012.

CAVALCANTI, C.. Desenvolvimento e Meio Ambiente: o conflito do Complexo Industrial-Portuário de Suape, Pernambuco. IV Encontro Nacional da Anppas. Brasília, 4, 5 e 6 de junho de 2008. Anais.
COMISSÃO INTERMINISTERIAL PARA OS RECURSOS DO MAR. Agenda Ambiental Portuária. Brasília, Novembro de 1998. Disponível em: http:// www.antaq.gov.br/portal/pdf/MeioAmbiente/AgendaAmbiental.pdf. Acesso em: 11 nov. 2007.

COMPANHIA DOCAS DO ESPÍRITO SANTO. Complexo Portuário do Espírito Santo. Porto de Vitória/Tubarão. Disponível em: http://www.portodevitoria.com.br/site/. Acesso em: jan. 2012.

COMPANHIA DOCAS DO RIO DE JANEIRO. Estudo de Impacto Ambiental - EIA. Projeto de Dragagem do Canal de Acesso e das Bacias de Evolução dos Terminais do Porto do Rio de Janeiro e de Niterói. Rio de Janeiro: CDRJ, Setembro, 2002. Disponível em: http://www.portosrio.gov.br/downloads/EIA_Dragagem_2002.pdf. Acesso em: mar. 2011.

. Termina a dragagem no Porto do Rio de Janeiro. InformASSCOM. Notas. Disponível em: http:// netserver4.portosrio.gov.br/asscom/docs/Dragagem. pdf. Acesso em: nov. 2011.

História do Porto do Rio de Janeiro. Disponível em: http://www.portosrio.gov.br/node/8. Acesso em: jan. 2012.

CONSELHO NACIONAL DO MEIO AMBIENTE. Resolução $N^{\circ}$ 001, de 23 de janeiro de 1986. Brasília: DOU de 17/02/86.

Resolução $N^{o}$ 344, de 25 de março de 2004. Brasília: DOU de 07/05/2004.

COSTA, C. A. S. Ética, sociedade e meio ambiente: uma proposta interdisciplinar. Revista Desarrollo Local Sostenible. Vol. 2, Nº 6, octubre, 2009. Disponível em: http://www.eumed.net/rev/delos/06/casc.htm. Acesso em: ago. 2011.

COSTA, Helena A.; BURSZTYN, Maria Augusta A.; NASCIMENTO, Elimar P. do. Participação Social em Processos de Avaliação Ambiental Estratégica. Revista Sociedade \& Estado, Brasília, v. 24, n. 1, p. 89-113, 
jan/abr. 2009. Disponível em: http://www.scielo.br/pdf/ se/v24n1/a05v24n1.pdf. Acesso em: 12 nov. 2011.

COUTINHO, H. D.; BARBOSA, A. R. Fitorremediação: Considerações Gerais e Características de Utilização. Silva Lusitana 15(1): 103-117. EFN, Lisboa. Portugal, 2007.

DUBOIS, V.; ABRIAK, N. E.; ZENTAR, R.; BALLIVY, G. The use of marine sediments as a pavement base material. Waste Management. Volume ${ }^{\circ}$ 29. $\mathrm{p}$ 774-782. 2009.

FARRA, A. D.; RODRÍGUEZ, C. A. Utilización de geosintéticos en defesa de márgenes - Casos de Obras. Instituto de Recursos Hídricos. Facultad de Ciencias Exactas y Tecnologías, Universidade Nacional de Santiago del Estero, Anais Argentina, 2003.

\section{FUNDAÇÃO ESTADUAL DE ENGENHARIA DO} MEIO AMBIENTE. DZ $1845 R$-3. Diretriz para o licenciamento ambiental de dragagem e disposição final de material dragado. Aprovada pela Comissão Estadual de Controle Ambiental - CECA/CN N ${ }^{\circ} 4.232$, de 26/11/2002. Disponível em: http://200.20.53.7/Ineaportal/Legislacao.aspx?ID=EC2F0291-AA60-4D29-B059-B6FC7BEDEA4A. Acesso em: jan. 2012.

FOLADORI, G. Limites do desenvolvimento sustentável. Campinas: Editora da UNICAMP, 2001.

GOES FILHO, H. de A. Dragagem e Gestão de Sedimentos. Rio de Janeiro, Dissertação (Mestrado em Ciências em Engenharia Civil) - COPPE/UFRJ, 2004.

GOUVEIA, M. Relatório de audiência pública sobre Projeto Morador será enviado ao Governo do Estado. 17 de Março de 2011. Disponível em: http://marygouveia. com.br/tag/suape/. Acesso em: out. 2011.

\section{GOVERNO DO ESTADO DE PERNAMBUCO. COM-} PLEXO INDUSTRIALPORTUÁRIO GOVERNADOR ERALDO GUEIROS. Suape comemora aniversário com mais uma obra. 08/11/2011. Disponível em: http://www. suape.pe.gov.br/news/matLer.php?id=66. Acesso em: jan. 2012.
O que é Suape ? Disponível em: http://www. suape.pe.gov.br/institutional/institutional.php. Acesso em: jan. 2012.

GOVERNO DO ESTADO DO ESPÍRITO SANTO. SECRETARIA DO MEIO AMBIENTE E RECURSOS HÍDRICOS. INSTITUTO ESTADUAL DE MEIO AMBIENTE E RECURSOS HÍDRICOS. VALE S.A. Ata da Audiência Pública do Projeto de Dragagem de Aprofundamento Complexo Portuário de Tubarão, da Vale S.A., Vila Velha, 27 de maio de 2010. http://www.meioambiente.es.gov.br/download/ VALE2705.pdf. Acesso em: jan. 2012.

INTERNATIONAL ORGANIZATION FOR STANDARDIZATION. ISO 9.000 GERENCIAMENTO DA QUALIDADE; ISO 14000 GESTÃO AMBIENTAL; e ISO 14010 AUDITORIA AMBIENTAL. http://www.iso.org/iso/home.html

KITZMANN, D.; ASMUS, M. Gestão Ambiental Portuária: desafios e possibilidades. RAP. Rio de Janeiro 40(6): 1041-60, Nov./Dez. 2006.

KOENING, M. L. ESQUINAZI-LEÇA, E.; NEUMANN-LEITÃO, S.; MACÊDO, S. J. Impactos da construção do Porto de Suape sobre a comunidade fitoplanctônica no estuário do rio Ipojuca (Pernambuco-Brasil). Act. bot. brasil. 16(4): 407-420, 2002.

KURY, K. A.; REZENDE, C. E.; PEDLOWSKI, M. A. O entendimento da população de São João da Barra do Mega-empreendimento do Complexo Portuário e Industrial do Açu em seu cotidiano. Anais V Encontro Nacional da Anppas. 4 a 7 de outubro de 2010. Florianópolis, SC.

LEAL NETO, A. de C. A expansão do terminal de contêineres de Sepetiba: uma aplicação da dinâmica de sistemas e considerações ambientais. Rio de Janeiro, Dissertação (Mestrado em Ciências em Planejamento Energético) - COPPE/UFRJ, 2000.

LLX. Complexo Industrial do Superporto do Açu. Disponível em: http://www.llx.com.br/cgi/cgilua.exe/ sys/start.htm?sid=162\&lng=br. Acesso em: jan. 2012. 
LONDON [DUMPING] CONVENTION, 1972. Documentos. Disponível em: http://www.imo.org/ blast $/$ mainframemenu.asp?topic_id $=617$. Acesso em: jan. 2012.

LUNDIN, G. M.; ESCOBAR, L. G.; STEPHENS, T. Cursos d'água e lagoas contaminadas com PCB (Bifenois policlorados) de polpa de papel são contidas e desidratadas usando unidades Geotube, proporcionando uma solução ambiental econômica. Duas localizações são apresentadas. 8th IWA Symposium on Forest Industry Wastewaters, Anais Vitória, ES, 2006.

MARINHADO BRASIL. NORMAM-11/DPC. Portaria $\mathrm{N}^{\circ} 27$, de 12 de maio de 1998. Disponível em: https://www.dpc.mar.mil.br/normam/N_01/normam01. pdf. Acesso em: jan. 2012.

MINISTÉRIO PÚBLICO FEDERAL. Sobre a instituição Ministério Público. Disponível em: http://www. pgr.mpf.gov.br/conheca-o-mpf/sobre-a-instituicao. Acesso em: jan. 2012.

MINISTÉRIO DO PLANEJAMENTO, ORÇAMENTO E GESTÃO. PAC 1. Resultados 2007-2010. Portos. Disponível em: www.planejamento.gov.br. Acesso: dez. 2011.

PAC 2. Balanço 2. Eixo Transportes. Disponível em: http://www.planejamento.gov.br/ PAC2/2Balanco. Acesso em: jan. 2012.

MINISTÉRIO DOS TRANSPORTES. GEIPOT - Empresa Brasileira de Planejamento de Transportes. A Reforma Portuária Brasileira. Brasília, Setembro de 2001.

MONTEIRO, M. T. Fitorremediação de rejeito contaminado proveniente do Canal do Fundão, na Baía de Guanabara-RJ. Rio de Janeiro, Tese (Doutorado em Engenharia Civil) - COPPE/UFRJ, 2008.

ORGANIZATION FOR DEVELOPMENT AND ECONOMIC COOPERATION. Environmental Assessment Handbook for Port Development Projects. The Overseas Coastal Area Development Institute of Japan. Japão, 1993.
PORTO, M. M.; TEIXEIRA, S. G. Portos e o desenvolvimento. São Paulo: Lex Editora, 2002.

PORTO, M. M. Portos e Meio Ambiente. São Paulo: Aduaneiras, 2007.

(a). Uma nova proposta para a Agenda Ambiental Portuária. XIX Cooperaportos - Cooperação Técnica e Operacional entre as Administrações Portuárias. Brasília, Outubro/Novembro de 2008. Anais.

(b). Infraestrutura e logística retroportuária de Itaguaí/RJ. Fórum Itaguaí, RJ, 2008. Disponível em: http://www.antaq.gov.br/portal/pdf/palestras/ MarcosMaiaPortoApresentaçãoForoItaguai08.pdf. Acesso em: 11 dez. 2010.

Revisão da Resolução CONAMA No 344/2004. 9 de dezembro de 2011. (mimco).

REDE MANGUEMAR - PE. Porto de Suape quer acabar com a pesca. 29 de setembro de 2010. Movimento dos Pescadores e Pescadoras Artesanais. Disponível em: http://manguemarpernambuco.blogspot. com.br/2010/09/porto-de-suape-quer-acabar-com-pesca.html. Acesso em: fev. 2012.

SÁ, M. E. M. Análise comparativa entre os Portos do Recife e de SUAPE: Desafios para a Gestão Ambiental. Recife, Dissertação (Mestrado em Gestão e Políticas Ambientais) - UFP, 2008.

SOUZA, T. N.; OLIVEIRA, V. de P. S. Conflito socioambiental entre atividades de pesca artesanal marinha e implantação de atividades portuárias no Norte Fluminense. Boletim do Observatório Ambiental Alberto Ribeiro Lamego, Campo dos Goytacazes/RJ, v.4, n.2, p.219-229, jul./dez. 2010.

TORRES, R. J. Uma Análise Preliminar dos Processos de Dragagem do Porto do Rio Grande, RS. Rio Grande, RS, Dissertação (Mestrado em Engenharia Oceânica) - Fundação Universidade Federal do Rio Grande, 2000. 
THEODORO, S. H. (org.). Mediação de conflitos socioambientais. Rio de Janeiro: Garamond, 2005.

VALE S.A.; CEPEMAR - SERVIÇOS DE CONSULTORIA EM MEIO AMBIENTE LTDA. RIMA - Relatório de Impacto Ambiental da Dragagem de Aprofundamento do Complexo Portuário de Tubarão. Relatório Técnico COM RT 008/10. Janeiro 10/Rev 00. Vitória, ES, 2010. Disponível em: http://www. meioambiente.es.gov.br/download/RIMA_CPM RT_008_10.pdf. Acesso em: jan. 2012.

VIEIRA, I. Porto do Rio de Janeiro amplia capacidade de operação. Agência Brasil. 03/09/2011. Disponível em: http://agenciabrasil.ebc.com.br/ noticia/2011-09-03/porto-do-rio-de-janeiro-amplia-capacidade-de-operacao. Acesso em: jan. 2012.

ZANDONADI, D. Vale investirá R $\$ 2$ bi no ES. Porto vai ganhar dragagem para receber navios maiores. 28/02/2011. A Gazeta. Disponível em: http://gazetaonline.globo.com/_conteudo/2011/03/787840-ale+investira $+\mathrm{r}+2+\mathrm{bi}+$ no + es.html. Acesso em: jan. 2012.

ZENTAR, R.; ABRIAK, N. E.; DUBOIS, V. Effects of salts and organic matter on Atterberg limits of dredged marine sediments. Applied Clay Science. Volume ${ }^{\circ}$ 42 p 391-397. 2009. 